\title{
In-Vitro Study of Novel Organic/ Inorganic Composite Scaffold For Bone Regeneration
}

\author{
Khairy M. Tohamy ${ }^{1}$, Islam E. Soliman ${ }^{1}$, Mostafa Mabrouk ${ }^{2}$ and Mohamed A. \\ Aboelnasr ${ }^{1}$ \\ ${ }^{1}$ Biophysics Branch, Faculty of Science, Al-Azhar University, Nasr \\ City 11884, Cairo and ${ }^{2}$ Refractories, Ceramics and Building materials \\ Department, (Biomaterials group), National Research Centre, 33El \\ Bohouth st.(former EL Tahrir st.)-Dokki-P.O.12622-Giza-Egypt.
}

\begin{abstract}
T N THIS STUDY, polysaccharide polymers /Hydroxyapatite composite scaffolds were prepared by using freeze-drier processing technique. The microstructure and morphology as well as mechanical strength of the scaffolds were characterized by XRD, FTIR, SEM, EDX and other methods. The porosity ratio and in vitro biomineralization of the scaffold were also evaluated. It was found that, both porosity and compressive strength are strongly dependent on the concentration of HA. The porosity was reduced from $\approx 87 \pm 5.1 \%$ to $66.7 \pm 3.2 \%$, while the mechanical measurements revealed that, the compressive strength reaches the highest value $23.96 \pm 0.82 \mathrm{MPa}$ by adding HA to hybrid polymers. In addition, Blended hydroxyethylcellulose to sodium alginate cause increase of total pore volume inside scaffold, decrease in mechanical properties and the presence of bioceramic inside scaffolds structure enhances the precipitation and biomineralization of HA from SBF on scaffolds surface. Thus results suggest that these biocompatible composite scaffolds can be useful for bone tissue regeneration.
\end{abstract}

Keywords: Polysaccharide, hydroxyapatite, Alginates, SBF.

\section{Introduction}

In the bone tissue engineering field, the scaffolds play an important and critically roles in new bone tissue formation at site which have defects ${ }^{(1)}$, and has to fulfill a few basic requirements, that is, high porosity and proper pore size, required surface properties permitting cell adhesion, differentiation and proliferation, desirable mechanical integrity to maintain the predesigned tissue structure, non-cytotoxicity and osteoconductivity ${ }^{(2-4)}$. The selection of the most suitable material to produce a scaffold to be used in bone tissue engineering application is a critically important step towards the construction of a tissue-engineered product, since its properties will determine the properties of the scaffold ${ }^{(5,6)}$

Biopolymer scaffolds degradability is one of the main key for designation and fabrication of biomimetic scaffolds in skin tissue engineering applications. Scaffolds should mimic the structure and biological functions of natural extracellular matrix (ECM) as closely as possible to create a conductive living substrate that will induce cells to function naturally. Biodegradable polymers intended for tissue engineering are mostly tailored to decompose via hydrolytic and enzymatic degradable polymers (3). There are many factors affect the polymer degradation kinetics such as type of chemical bond, polymer molecular weight, crystallinity and the presence of cross links, fillers, additives and etc ${ }^{(5)}$.

Alginates are well known natural ionic polysaccharides used mainly as food additives, thickener, gelling agent, and in the controlled delivery of drugs ${ }^{(7)}$. Alginates are linear water-soluble polysaccharides 
including mannuronic acid (M) and guluronic acid $(G)$ at different ratio and different distribution in the chains. The physical and chemical properties of alginates carefully depend on their composition and the sequence of guluronic and mannuronic residues in the polymeric chain ${ }^{\mathbf{8}-10)}$.

Hydroxyethylcellulose (HEC) is hydrophilic biopolymers with low charge density. HEC is recognized as one of the natural macromolecules polysaccharides that comprised from $\beta$-D-glucose rings at the main chain. Strong hydrogen bonding among the hydroxyl groups of HEC makes it available to be employed in extensive utilizations due to its water solution properties ${ }^{(11,12)}$. Indeed, the remarkable physical properties associated with cellulose polymers is accumulate from their water and organic solvent solubility, thermal plasticity, thickening and colloid stabilizing abilities. Thereby, the chemical composition of HEC will allow to occupied large amount of relatively easily accessible hydroxyl units that can be attached by a number of functional groups ${ }^{(13,14)}$.

Based on previous reports, the blends of Hydroxyethylceloluse with alginate polysaccharide A/HEC was extensively used in biomedical application owing to its water soluble, biodegradable, non-toxic and biocompatible with low mechanical behaviors ${ }^{(15,16)}$. So that HAp added to the A/HEC scaffolds may not only improve the biocompatibility and mechanical properties but also enable manipulate bioactive molecule release from the scaffolds ${ }^{(17)}$.

In this study, scaffolds of pure alginate and a blend with hydroxyethylcellulose, with and without hydroxyapatite are prepared, in order to understand their effect on the physical properties of alginate. The effect of crosslinking with calcium ions is also analyzed. Prepared scaffolds are immersed in Simulated Body Fluid (SBF) and the ability to biodegradation and in vitro bioactivity will be examined.

\section{Materials and Methods}

\section{Materials}

Alginate (A) with molecular weight (Mw) of 500,000 g/mol, Hydroxyethylceloluse (C), $\mathrm{Mw}=90,000 \mathrm{~g} / \mathrm{mol}$, calcium chloride was employed as across linker, $\mathrm{Mw}=147.02 \mathrm{~g} / \mathrm{mol}$ and chemical reagents of SBF was employed as in-vitro bioactivity test, all precursor was obtained from Sigma Aldrich (chem. Lab, Germany). Calcite $\left(\mathrm{CaCO}_{3},>99 \% \mathrm{BDH}\right.$ Laboratories Ltd) and $\mathrm{Ca}_{2} \mathrm{HPO}_{4}$ (DCHP, > 99\% Phosphor Grade, Lumifax Ltd.), as a raw materials used to prepared monoclinic hydroxyapatite phase.

\section{Synthesis of monoclinic Hydroxyapatite powder}

Hydroxyapatite (HAp) was fabricated by utilizing solid state quenching technique as early reported by Morgan et al, (2000) (18) with small modification. In details, 81.666 g DCHP $\left(\mathrm{Ca}_{2} \mathrm{HPO}_{4}\right)$ and $39.930 \mathrm{~g}$ of calcite $\left(\mathrm{CaCO}_{3}\right)$ will be utilized to give $\mathrm{Ca} / \mathrm{P}$ ratio with 1.67 as a stoichiometric ratio of HAp. These raw materials were well blend using ball mill. Thereafter, the mixed powder was putted at $1000^{\circ} \mathrm{C}$ with air atmosphere for $3 \mathrm{~h}$ in electrical furnace.

\section{Fabrication of composite scaffolds}

S.A/HEC-HAp composite scaffolds were prepared by employing freeze drying technique. Firstly, Sodium alginate was dissolved in distilled water at $60^{\circ} \mathrm{C}$, for $15 \mathrm{~min}$ using concentration of $10 \mathrm{Wt} \%$. Then blend with this solution Hydroxyethylceloluse (HEC), $10 \mathrm{Wt} \%$, become total a polymer concentration of $20 \mathrm{Wt} \%(\mathrm{~W} / \mathrm{V})$. The HAp concentration $40 \%$ were added to the organic solution, as shown in Table (1) and continue stirred for overnight using a magnetic stirrer in order to break the HAp agglomerates and ensure a better (homogenous) distribution of HAp particles in the composite scaffolds. Composites were casted in Petri dish molds and kept at $-18{ }^{\circ} \mathrm{C}$ overnight, and freeze dried for $24 \mathrm{hr}$ then the all scaffolds were removed from the molds and immersed in 5 $\% \mathrm{CaCl}_{2}$ for $3 \mathrm{hr}$ to crosslinking, removed, washing three times by distilled water, after that kept in the desecrator for further analysis as mentioned below.

TABLE 1. Different composite scaffolds.

\begin{tabular}{cccc}
\hline Sample & \multicolumn{3}{c}{ Sample base (wt \%) } \\
\hline & A & HEC & HAp \\
\hline A & 100 & 0 & 0 \\
AC & 50 & 50 & 0 \\
ACHp & 50 & 50 & 40 \\
\hline
\end{tabular}




\section{Characterization of integrated samples}

Differential scanning calorimetry (DSC) and thermal gravimetric analysis (TGA) were carried out using a computerized SETARAM labsys ${ }^{\mathrm{TM}}$ TG-DSC thermal analysis system range of $25-1000{ }^{\circ} \mathrm{C}$ with a heating rate of $10{ }^{\circ} \mathrm{C} / \mathrm{min}$. XRD patterns of the samples have been measured using [Axs D8 ADVANCE] with $[\mathrm{Cuk} \alpha=1.54056 \AA]$ radiation. The maximum current and voltage is $40 \mathrm{~mA}$ and $40 \mathrm{Kv}$. XRD was taken at $2 \theta$ angle range of $10-70^{\circ}$ and the process parameters were: scan step size $0.02(2 \theta)$ and scan step time 0.05 s. Fourier transform infrared (FTIR) spectroscopy measurements were recorded at room temperature in the range 400$4000 \mathrm{~cm}^{-1}$, with Model 580, Perkin-Elmer. Dried composite scaffolds were ground and mixed thoroughly with $\mathrm{KBr}$ at a ratio of 1:5 (Sample: KBr). The surface of the scaffold samples were examined by scanning electron microscope (model XL30, Philips) attached with element analysis of X-Ray (EDX) unit, with accelerating voltage 30 $\mathrm{KV}$, magnification up to $400,000 \mathrm{x}$ and its resolution is $(3.5 \mathrm{~nm})$. SEM micrographs was obtained after coating the samples with Gold using Edwareds 5150 sputter coating (England).

\section{Mechanical behaviors of Scaffolds}

The mechanical properties of the composites scaffolds were evaluated by measuring the compressive strength and Deformation Energy of prepared sample using a Texture Analyzer (TA.XTplus Stable Micro systems, Surrey, UK). The specimens were evenly cut from the most homogeneous region of the scaffolds to form blocks with dimensions of $10 \times 5 \times 5 \mathrm{~mm}^{3}$. These sample scaffolds were situated between parallel plates utilizing a component EMIC DL 3000 and compressed with a crosshead speed of $0.5 \mathrm{~mm} /$ $\min$ and a $1.0 \mathrm{kN}$ load cell. Minimum three pieces $(n=3)$ of each composite scaffold Specimens were investigated and take averaged. The Deformation Energy (DE) is defined as the absorbed energy that causes deformation of the elastic scaffold; The Rigidity Gradient (RG) refers specifically to the scaffold unit migration guided by gradients in substrate rigidity. Both DE and RG were used as two system examination to estimate mechanical behavior for prepared composite samples ${ }^{(19)}$.

\section{Porosity Estimation}

Liquid displacement method was used to determine the porosity of the scaffolds ${ }^{(20)}$. Three samples each of specimens were submersed in glycerol for $1 \mathrm{hr}$ and then centrifugation at 5000 $\mathrm{rpm}$ for $15 \mathrm{~min}$, after that left at room temperature for $48 \mathrm{hr}$ and the porosity of the sample was determined using Eq. (1)

$$
\mathrm{P} \%=\left[\left(\mathrm{W}_{1}-\mathrm{W}_{3}\right) /\left(\mathrm{W}_{2}-\mathrm{W}_{3}\right)\right] \times 100
$$

Where $\mathrm{W}_{1}$ : weight of the scaffold before immersion, $\mathrm{W}_{2}$ : weight of the scaffold after immersion and $\mathrm{W}_{3}$ : weight after drying. By this method we can just get the porosity percentage (P\%).

\section{In- vitro studies}

\section{In-vitro biomineralization studies}

In vitro bioactivity of the scaffolds was investigated by immersion in simulated body fluid (SBF) solution at $37^{\circ} \mathrm{C}$ as proposed by Kokubo et al. ${ }^{(21,22)}$. In-vitro bioactivity of the scaffolds reflected in their capability for formation of hydroxyapatite layer onto their surface ${ }^{(23)}$. SBF contains the same concentrations of inorganic ions as human plasma. We carried out in vitro studies by soaking samples $\left(10 \times 10 \times 5 \mathrm{~mm}^{3}\right)$ in $\mathrm{SBF}$ solution $(60 \mathrm{ml}, \mathrm{pH}=7.4)$. The sample-SBF mixtures were immediately sealed into sterilized containers, and were stored in an incubator at $37{ }^{\circ} \mathrm{C}$ for 28 days ${ }^{(7)}$. After soaking, the samples were removed and putted on filter paper, washed by distilled water, and dried in air. The surface changes were then investigated through XRD, SEM, EDX and FTIR measurements.

\section{Results and Discussion}

XRD of Hydroxyapatite powder as fillers at different conditions

The XRD technique was employed to identify obtained phases and assess the phase purity, the level of crystallinity and crystallographic changes that occur in hydroxyapatite due to the effect of incorporation foreign ions within it ${ }^{(24)}$.

The X- ray diffraction patterns of the prepared HAp powders are shown in Fig.1a. There are two different conditions were used with and without air in electric furnace. The peaks assigned to the structure of hydroxyapatite just matches with the ICDD (JCPDS No.076-0694). It is observed that, the principle diffraction peaks of HAp were appeared at $2 \theta$ value of about $25.6^{\circ}$ and a triple peaks in the range $\left(30^{\circ}\right.$ to $\left.35^{\circ}\right)$. For the peak located at $2 \theta$ equal to $25.6^{\circ}$, the characteristics reflection $(h k l)$ is $\left(\begin{array}{lll}0 & 0 & 2\end{array}\right)$ and for triplet peaks located at $2 \theta$ in the range $\left(30^{\circ}\right.$ to $\left.35^{\circ}\right)$ the 
characteristics reflection are (2 $\left.1 \begin{array}{ll}2 & 1\end{array}\right),\left(\begin{array}{lll}1 & 1 & 2\end{array}\right) \&\left(\begin{array}{l}3 \\ 0\end{array}\right.$

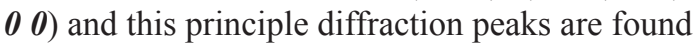
on all prepared samples ${ }^{(25)}$.

The another phase which can be observed at $1000{ }^{\circ} \mathrm{C}$ calcined, $\mathrm{CaCO}_{3}$ conversion to $\mathrm{CaO}$, peak of $\mathrm{CaO}$ appears at $37.4^{\circ}$ and $53.8^{\circ}$ these phases may be attributed to the incomplete calcinations conditions and more abundance $\mathrm{Ca}$ ${ }^{2+}$ ions inside scaffolds sample beside oxygen ions in solution dissolved ${ }^{(25)}$. According to XRD results of the two prepared HA powder samples with and without vacuum system; there is no clear difference in position peaks of the samples with a small enhancement in the intensity of strongest peak in the sample which prepared by vacuum system, as shown in Fig. 1(a1).

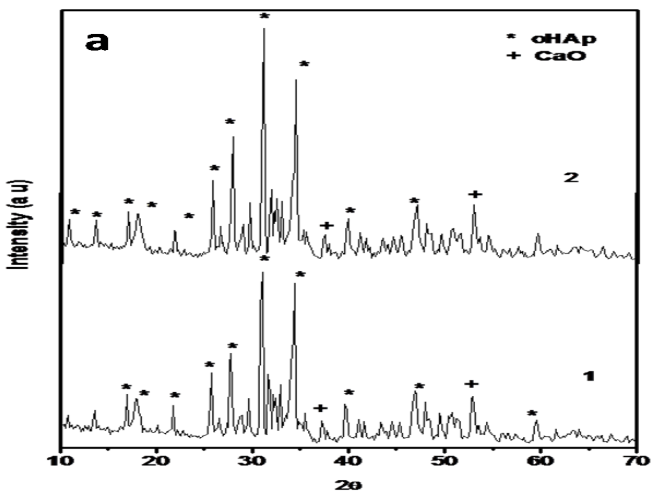

FTIR of Hydroxyapatite powder as fillers at different conditions

FTIR is employed to confirm the presence of groups which show all characteristic absorption bands pertaining to hydroxyapatite see Fig.1b. The functional groups of hydroxyapatite revealed by FTIR analysis are:

Hydroxyl bands: There are two hydroxyl absorption bands, one is located at a range from 630 to $636 \mathrm{~cm}^{-1}$ (bending mode) and the other is located at a range from 3500 to $3573 \mathrm{~cm}^{-1}$ (stretching mode) ${ }^{(26)}$.

Phosphate bands: There are four vibrational modes present for phosphate groups, v1, v2, v3 and $v 4$. All these modes are infrared active. The $v 1$ band corresponding to P-O stretching vibrational

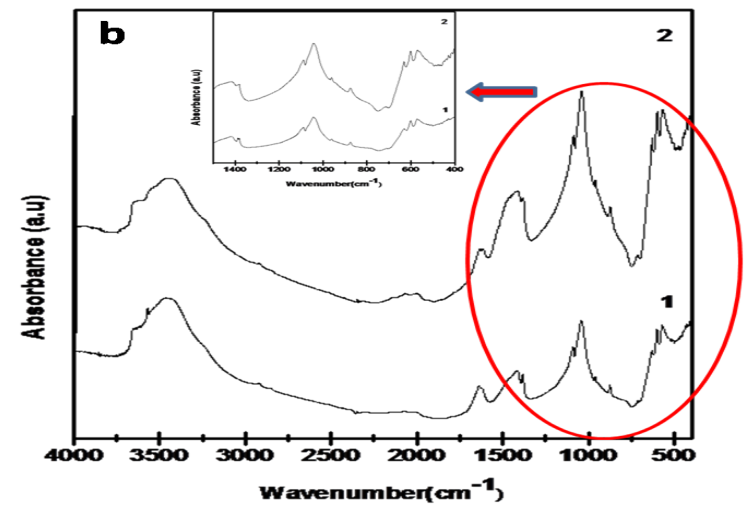

Fig. 1:( a XRD and b) FTIR of HAp powder at two different conditions; 1) HAp powder without air technique; 2) HAp powder with air technique.

mode is located at a range from 955 to $970 \mathrm{~cm}^{-1}$ which appears as a single peak, whereas a small band is located at around $460-476 \mathrm{~cm}^{-1}$ and is ascribed to the O-P-O bending mode v2. The v3 band corresponding to $\mathrm{P}-\mathrm{O}$ stretching vibrational mode is located at a range $976-1110 \mathrm{~cm}^{-1}$ which appears as doublet peaks in the spectrum. The $v 4$ corresponding to O-P-O bending mode is present as doublet peak, the first is located at around 660 $\mathrm{cm}^{-1}$ and the second is located at around $520 \mathrm{~cm}^{-1}$ $(27,28)$.

$\mathrm{H}_{2} \mathrm{O}$ bands: There are two sites of absorption bands, one is the broad absorption band located at $1600-1654 \mathrm{~cm}^{-1}$ reflecting $\mathrm{H}-\mathrm{O}-\mathrm{H}$ bending mode and the other one is the band located at 3200-3550 $\mathrm{cm}^{-1}$ which may come from lattice $\mathrm{H}_{2} \mathrm{O}^{(29)}$.

Carbonate bands: Hydroxyapatite structure is slightly different compared to the synthetic one most likely due to the presence of $\mathrm{CO}_{3}^{-2}$ groups on it. Theoretically, carbonate groups have four or five vibrational modes, three of them are observed in the infrared spectrum ${ }^{(30)}$. The carbonate $v 4$ bands have very low intensity and are rarely seen in the infrared spectrum while $v 2$ and $v 3$ vibrational mode are observed in the infrared spectrum. v3 carbonate vibrational mode is located in the region of 1300$1600 \mathrm{~cm}^{-1}$ and $v 2$ is located at $870-876 \mathrm{~cm}^{-1}$. The carbonate absorption bands indicate that carbonate anions had been substituted for certain phosphate positions in the apatite lattice (B-type substitution). In precipitated biological apatite, the predominant substitution appears to be $\mathrm{CO}_{3}^{-2}$ anions for $\mathrm{PO}_{4}^{-3}$ anions, but usually $\mathrm{PO}_{4}^{-3}$ may replace small amount of $\mathrm{OH}^{-1}$ ion (A-type substitution) ${ }^{(31)}$.

In addition, from Fig.1b FTIR data showed that, three bands located at $560,605 \mathrm{~cm}^{-1}$ attributed to P-O and $630 \mathrm{~cm}^{-1}$ assigned to hydroxyl group, these three bands more appearance in sample prepared with vacuum system, Therefore, the best monoclinic HAp phase used as filler in present study was prepared with vacuum system at $1000{ }^{\circ} \mathrm{C}$. 


\section{Thermal analysis}

The thermo-gravimetric data for sample are reported in Fig.2. In TGA curves we can distinguish four regions. The first region from room temperature to $180{ }^{\circ} \mathrm{C}$, the mass loss is associated with the elimination of water which remaining in the scaffolds, that confirmed by first endothermic peak in DSC curve ${ }^{(7,32,33)}$; the second region between $180{ }^{\circ} \mathrm{C}$ and $350{ }^{\circ} \mathrm{C}$, the mass loss is associated to the degradation of polysaccharides network, Compatible with the first exothermic peak of DSC curve ${ }^{(34,35)}$. Third region above $350{ }^{\circ} \mathrm{C}$ to $\approx 550{ }^{\circ} \mathrm{C}$, may be attributed to degradation of calcium alginate, degradation step, $\mathrm{Na}_{2} \mathrm{CO}_{3}$ and other carbonaceous materials ${ }^{(36-38)}$ and the final fourth region above
$550{ }^{\circ} \mathrm{C}$ associated degradation $\mathrm{Ca}(\mathrm{OH})_{2}$ and crystallization temperature, that confirmed by second exothermic peak in DSC curve ${ }^{(39-42)}$.

\section{Mechanical properties}

Alginate / Hydroxyethylceloluse with HAp scaffolds were tested for the Compressive Strength (CS) and Deformation Energy (DE) properties in dry conditions ${ }^{(43)}$. It was a significant observation that $\mathrm{CS}$ results refers to firstly decrease from $10.13 \pm 0.51$ to $8.83 \pm 0.34 \mathrm{MPa}$ from $\mathrm{A}$ to $\mathrm{AC}$, with addition $40 \%$ concentration of HA gradually increased to $23.96 \pm 0.82 \mathrm{MPa}$ as shown in Fig. 3a. DE results refers to firstly decrease from $A$ to $\mathrm{AC}, 100 \pm 10$ to $90 \pm 10.5 \mathrm{Joule} / \mathrm{m}^{3}$, after that gradually increase with filler content to $182 \pm 16$ Joule $/ \mathrm{m}^{3}$ for ACHp as shown in Fig. $3 b^{(44,45)}$.

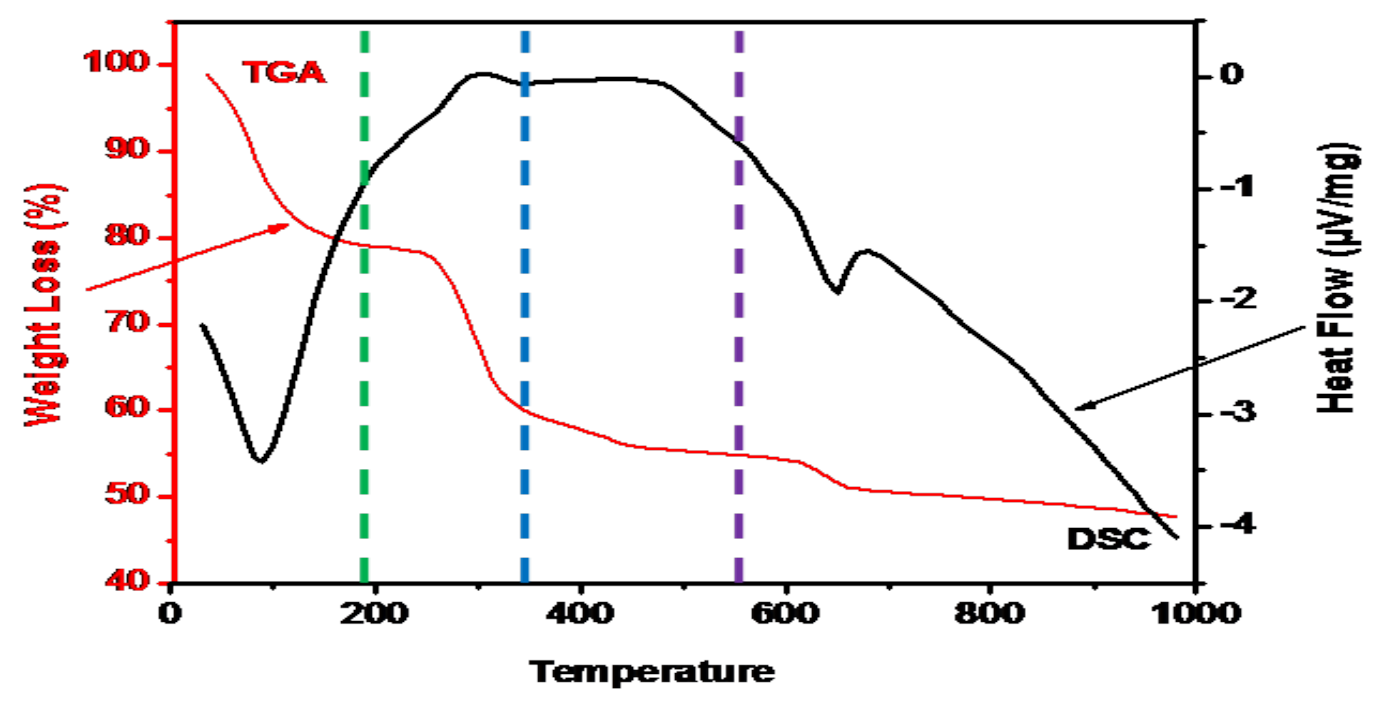

Fig. 2. DSC and TGA thremograms of ACHp scaffold sample.
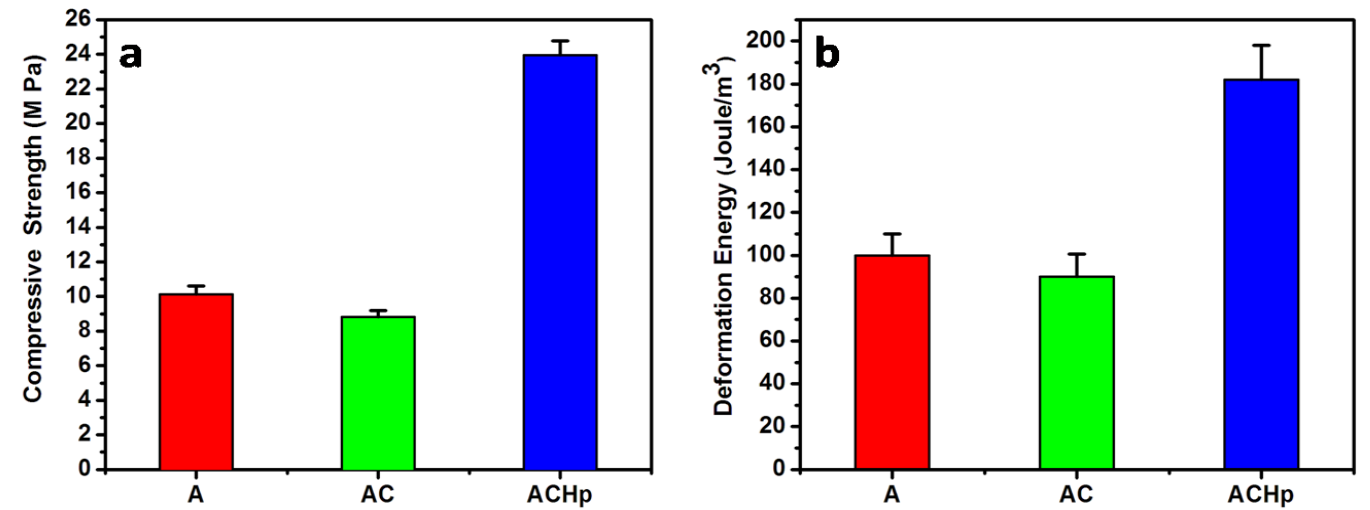

Fig. 3. Mechanical properties images of prepared scaffolds sample, a) CS; b) DE. 
The results indicated that the higher HA content the higher CS, and DE compared with the SA and HEC native polymer. These results are due to HEC when blended to alginate polysaccharides lead to increasing in total pores volume and pores diameter, while higher HA content causing a decrease in pores diameter.

\section{Porosity studies}

Liquid displacement technique was employed to estimated porosity ratio of the prepared scaffold. The porosity of the alginate control scaffolds, alginate / Hydroxyethylceloluse and $\mathrm{A} / \mathrm{C}$ with HA composite scaffolds are shown in Fig. 4a. The percentage of porosity was found increase from $\approx 82 \pm 4.3 \%$ in $\mathrm{A}$ to $87 \pm 5.1 \%$ in $\mathrm{AC}$ after that decrease to $66.7 \pm 3.2 \%$ for ACHp. Porosity is essential for the transport of oxygen and nutrients to the interior of the scaffolds. A reduction in porosity percentage of the composite scaffolds was observed, but this controlled porosity is satisfactorily favorable for tissue engineering applications,

The presence of HAp in the composite scaffold supports tissue in-growth. Porosity offered by the composite scaffold enhances the bone bonding ability due to the following reasons (a) high surface area to volume ratio offered by HAp has the tendency to bioresorb and induces bioactivity, (b) interconnected pores can provide a framework for bone growth into the matrix of the implant, and thus anchor them with the surrounding bone, preventing micro-motion that in turn increases further bone growth, (c) interconnected porosity is also a source of nutrient supply, vascularization and waste removal ${ }^{(46-48)}$.
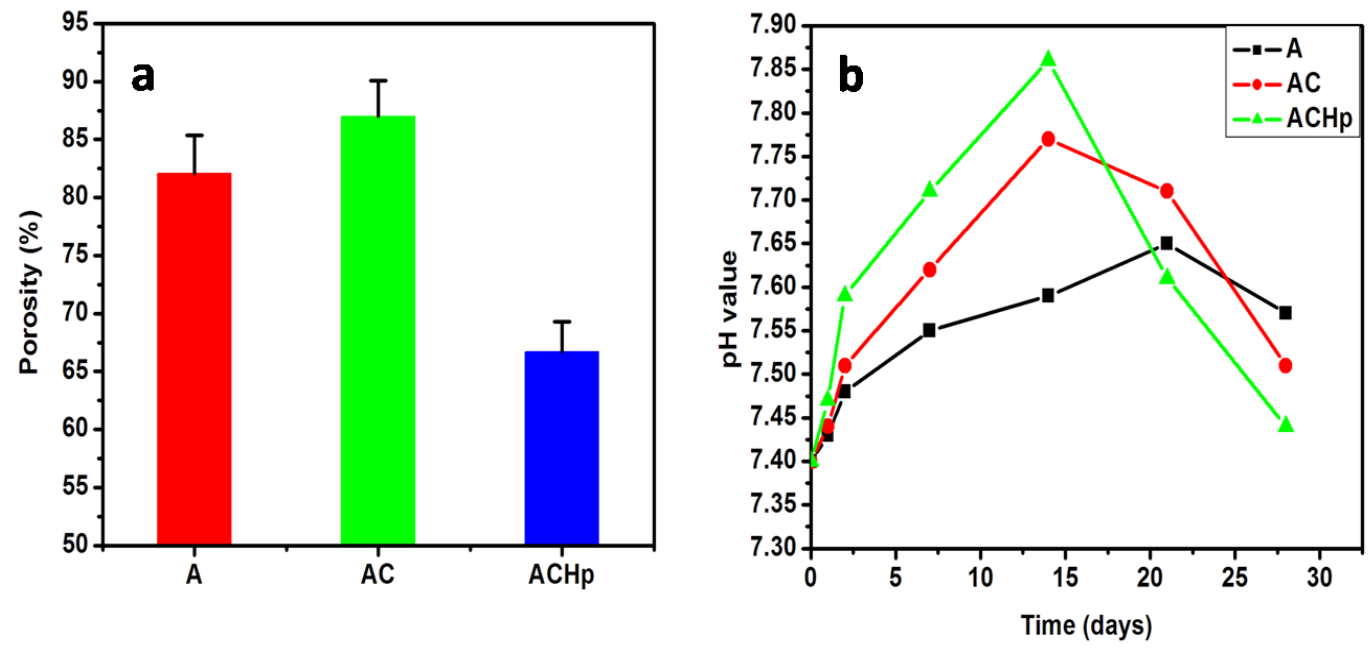

.Fig. 4 a: porosity by liquid displacement; b: pH values for SBF solution

\section{Interpretation of the $\mathrm{pH}$ measurement}

The $\mathrm{pH}$ measurement test is an analytic technique which focuses on the earliest stages of the reactions to one composition of bioactive scaffolds with simulated body fluid (SBF) ${ }^{(38)}$. The $\mathrm{pH}$ value has multiple effects on bone cells metabolism and function. The most important and interesting is that when bone forms, the crosslinking of the collagen chains and the subsequent precipitation of hydroxyapatite are $\mathrm{pH}$ dependent and require an optimally $\mathrm{pH}$ at the bone formation site ${ }^{(19)}$.

The changes in $\mathrm{pH}$ of the SBF solution after immersion of samples for a period of 28 days are presented in Fig. 4b. It was observed, that $\mathrm{pH}$ of SBF increases to a large extent (7.4 to 7.86 ) for ACHp after 15 days from started immersed due to ion release $\left(\mathrm{Ca}^{2+}\right)$ from scaffolds sample. After this period, the $\mathrm{pH}$ of SBF gradually decreased because the ion from SBF re-precipitated on surface scaffolds sample such as $\mathrm{Ca}$ and $\mathrm{P}$ which initial stage for hydroxyapatite formation ${ }^{(19,49)}$.

\section{Elemental analysis in SBF}

Inductively Coupled Plasma (ICP) has been used to detect the concentration of calcium and phosphorus ions released and re-precipitated on the surface of the prepared samples upon immersion in SBF. 


\section{Calcium concentration}

Changes in SBF composition after soaking of scaffolds during a period of 28 days are illustrated in Fig. (5a). As can be seen, $\mathrm{Ca}^{2+}$ concentration in SBF increased from $89.26 \mathrm{ppm}$ to 99.22 and then 111.55 ppm for A after 2 day and 15 days respectively and then decrease gradually until reached to $67.78 \mathrm{ppm}$ at the end of evaluating period. In AC and ACHp scaffold samples, the $\mathrm{Ca}^{2+}$ concentrations increased with respect the original value, reaching 130.22 and $183.95 \mathrm{ppm}$ respectively on 7 days, after that decrease to reach 54.61 and 19.09 ppm respectively ${ }^{(50,51)}$.

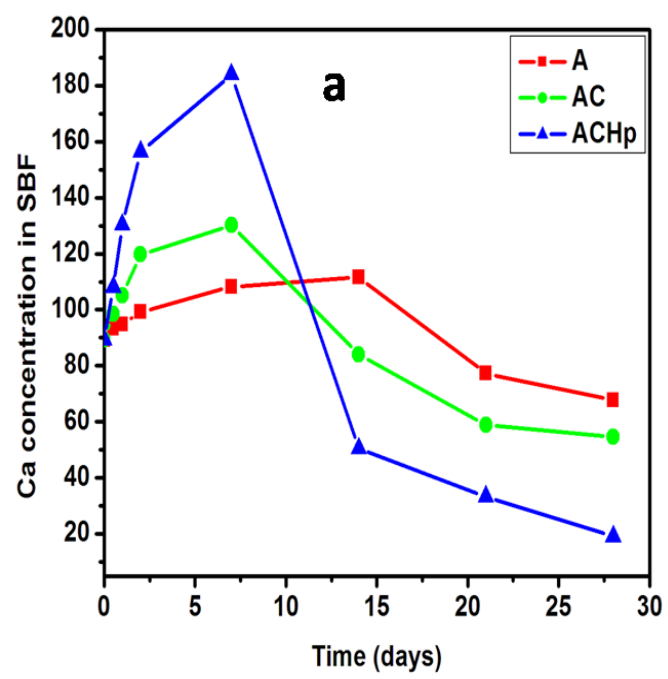

\section{Phosphorus concentration}

The variations relating to immersion times of $\mathrm{P}^{5+}$ concentrations in SBF after immersion of the prepared scaffold samples are shown in Fig. 5 b. The $\mathrm{P}^{5+}$ concentrations decreased gradually from $39.027 \mathrm{ppm}$ reaching to $5.45,3.13$ and $0.046 \mathrm{ppm}$ for A, AC and ACHp scaffold samples respectively during 28 days immersion in $\mathrm{SBF}{ }^{(51)}$. According to results of elemental analysis (Ca and $\mathrm{P}$ concentration in SBF), increasing and decrease in $\mathrm{Ca}$ ions in $\mathrm{SBF}$ and permanent decreasing in $\mathrm{P}$ ions, can be explained the formation of hydroxyapatite on scaffolds surface. Thus, this is indication to the formation of the apatite layer in the ACHp sample more than in samples A and $\mathrm{AC}$, this due to the presence of hydroxyapatite

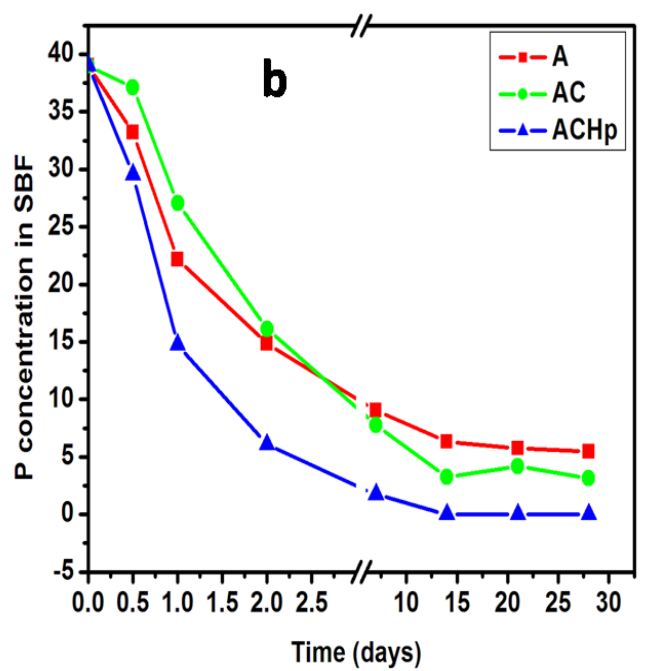

Fig. 5. Elemental concentration in SBF, a) Ca concentration; b) P concentration.

phase in ACHp sample from its counterpart in the other prepared samples.

\section{SEM and EDX Analysis}

It is noteworthy that SEM analysis is only a reliable technique to obtain information about $2 \mathrm{D}$ systems, i.e. investigate the macro and microstructure of the scaffold in a non-destructive way at the surface, and shows limited performance for assessing the pore interconnectivity of the materials. The SEM images shown in Fig. 6, it can be seen that $\mathrm{A} / \mathrm{AC}$ biopolymer scaffolds microarchitecture with and without HAp consists of a highly porous and open pore structure.

Figure $6 \mathrm{a}$ shows the interface of SA/HEC scaffold at the surface, where it is possible to observe the distinct porous layers. Fig. 6b shows a typical $\mathrm{A} / \mathrm{AC}$ pore at the $\mathrm{A} / \mathrm{C}-\mathrm{HAp}$ interface, although HA used as filler but with suitable pore size (more than $50 \mu \mathrm{m}){ }^{(37)}$. After 28 days of immersion scaffolds in SBF, the growth of white granule or layers can be observed on its scaffolds. So, scaffolds surface becomes covered with spherical forms layer of hydroxyapatite, this results confirmed with Ravindra V. B. et al 2017 (37). A notable contrast in the surface morphology between two scaffold investigated samples is seen after soaking in SBF, demonstrating the arrangement of apatite layer with different amount. The apatite layer (white areas) increased with blended HA to polysaccharides polymers as seen in Fig .6 c, d, more appearance with treatment investigated samples by flooding algorithm in SXWM software program. The blue areas 
represent the free-apatite (No apatite) sample surface, this area are large in the pure polymer sample A, but in the sample ACHp, this area is very small with increasing in apatite cover layer on surface scaffolds, as illustrated in Fig. 6e, f.

In order to ensure that the observed white granules ${ }^{(\mathbf{5 2})}$ on surface samples are really indicating to hydroxyapatite layers, the EDX measurements have been conducted for two prepared samples after 28 days from immersed in the SBF medium.
The obtained results of these investigations are showed in Fig. 6 e, f for A sample and ACHp sample after soaking in SBF.

Both spectra are described by a multi peaks, for the following elements $\mathrm{P}, \mathrm{O}, \mathrm{Cl}, \mathrm{Ca}, \mathrm{k}$, and $\mathrm{Na}$. A clear enhancement of the $\mathrm{Ca}$ and $\mathrm{P}$ peaks together with molar ratio between $\mathrm{Ca} / \mathrm{P}$ $=1.71$. This observation suggests that a good bonding exist between the two organic and
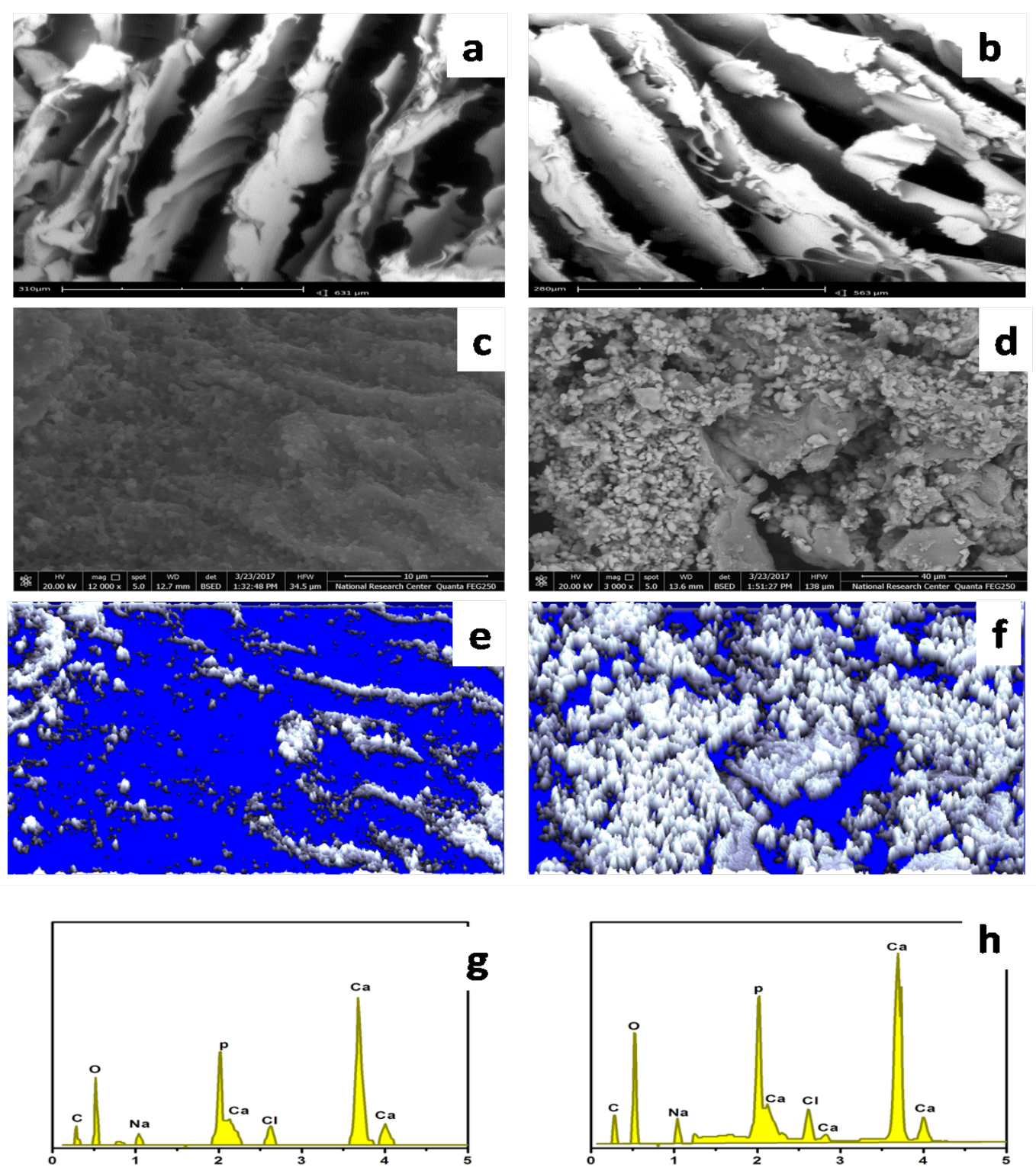

Fig. 6. (Top) SEM images of the scaffolds samples A and ACHp before soaking in SBF (a, b). (middle) The same SEM images after soaking in SBF for 28 days (c, d). (Bottom) SEM images after soaking in SBF with treatment by the flooding algorithm in SXWM software and EDX (e, f, g, h). The blue areas represent the free-apatite sample surface. 
inorganic components, which are known to be a requisite necessary to assure a good integrity and functionality of the bone cell ${ }^{(50)}$.

\section{Conclusion}

Polysaccharide polymers /Hydroxyapatite composite scaffolds were prepared by using freeze-draying technique. Polysaccharides polymer-based scaffold with 40\% HA (ACHp) has significantly improved mechanical strength as compared with its hybrid polymers AC. Also, it has stable structural due to the strong ionic bonding between the $\mathrm{Ca}$ groups of $\mathrm{HA}$ and the carboxyl groups of alginate. The alginateHydroxyethylceloluse scaffold with a porosity of $87 \pm 5.1 \%$ attained a compressive strength of $8.83 \pm 0.34 \mathrm{MPa}$ and DE of $90 \pm 10.5 \mathrm{Joule} / \mathrm{m}^{3}$ respectively, which are small values compared to the pure alginate scaffold. After that, addition of HA to nature polymers returned CS and DE to increasing to $23.96 \pm 0.82 \mathrm{MPa}$ and $182 \pm 16$ Joule/ $\mathrm{m}^{3}$ respectively. Incorporation of HA to polymers scaffold did not increased mechanical behavior only, but also helped to enhance precipitation of hydroxyapatite from SBF to scaffolds sample and thus increasing bioactivity. All these results suggested that ACHp composite scaffold can serve as an appropriate bioactive matrix for periodontal tissue regeneration.

\section{References}

1. Salgada AJ, Coutinho OP, Reis RL., Bone tissue engineering: state of the art and future trends. Macromol Biosci 4, 743-65 (2004).

2. Hutmacher DW., Scaffolds in tissue engineering bone and cartilage. Biomaterials 21(24), 2529-43 (2000).

3. Wang H., Li Y., Zuo Y., Li J., Ma S., Cheng L., Biocompatibility and osteogenesis of biomimetic nano-hydroxyapatite/ polyamide composite scaffolds for bone tissue engineering, Biomaterials. 28, 3338-3348 (2007).

4. Wang J., Wang M., Zheng M., Guo Q., Wang Y., Wang H., Xi X., Huang F., Gong R., Folate mediated self-assembled phytosterol-alginate nanoparticles for targeted intracellular anticancer drug delivery. Colloids Surf. B: Biointerface 129, 63-70(2015).

5. Ma PX., Scaffolds for tissue fabrication.
Mater Today 7(5), 30-40 (2004).

6. Guoping C, Takashi U, Tetsuya T., Scaffold design for tissue engineering. Macromol Biosci 2(2), 67-77 (2002).

7. Russo R., Abbate M., Malinconico M., Santagata G., Effect of polyglycerol and the crosslinking on the physical properties of a blend alginate-Hydroxyethylcellulose Carbohydrate Polymers 82, 1061-1067 (2010).

8. Russo, R., Malinconico, M., Petti, L. and Romano, G., Physical behavior of biodegradable alginate-poly(vinyl alcohol) blend films. Journal of Polymer Science, Part B: Polymer Physics, 43, 1205-1213 (2005).

9. Russo, R., Malinconico, M. and Santagata, G., Effect of cross-linking with calcium ions on the physical properties of alginate films. Biomacromolecules, 8, 3193-3197 (2007).

10. Sakugawa, K., Ikeda, A., Takemura, A. and Ono, H., Simplified method for estimation of composition of alginates by FTIR. Journal of Applied Polymer Science, 93, 1372-1377 (2004).

11. Eglin, D., Mortisen, D. and Alini M., Degradation of synthetic polymeric scaffolds for bone and cartilage tissue repairs. Soft Matter 5, 938 (2009).

12. Gopferich A., Mechanisms of polymer degradation and erosion. Biomaterials $x$ 17,103-14 (2009).

13. Sun W, Sun D, Wei Y, Liu S, Zhang S. Oil-in-water emulsions stabilized by hydrophobically modified hydroxyethyl cellulose: adsorption and thickening effect. J. Colloid Interface Sci; 311, 22836 (2007).

14. Farah H. Z., Fathima S., Mohammad A. R. \& Mashitah M. Y., In vitro degradation study of novel HEC/PVA/ collagen nanofibrous scaffold for skin tissue engineering applications. Polymer Degradation and Stability 110, 473-481 (2014).

15. Lee KY, Jeong L, Kang YO, Lee SJ, Park WH., Electrospinning of polysaccharides for regenerative medicine. Adv Drug

Egypt. J. Biophys. Biomed. Eng., Vol. 18 (2017) 
Deliv Rev 61, 1020-32 (2009).

16. Georgieva N, Bryaskova R, Tzoneva R., New polyvinyl alcohol-based hybrid materials for biomedical application. Mater Lett 88, 19-22 (2012).

17. Zhu N, Cooper D, Chen X-B, Niu CH., A study on the in vitro degradation of poly (1-lactide)/chitosan microspheres scaffolds. Front Mater Sci 7, 76-82 (2013).

18. Morgan H., Wilson R.M., Elliott J.C., Dowker S.E.P., Anderson P., Preparation and characterisation of monoclinic hydroxyapatite and its precipitated carbonate apatite intermediate, Biomaterials. 21, 617-627 (2000).

19. Mabrouk M., Choonara Y. E., Marimuthu T., Kumar P., du Toit L. C., Vuuren S., Pillay V., $\mathrm{Ca}_{3}(\mathrm{PO} 4)_{2}$ precipitated layering of an in situ hybridized PVA/ $\mathrm{Ca}_{2} \mathrm{O} 4 \mathrm{Si}$ nanofibrous antibacterial wound dressing. Int. Journal of Pharmaceutics 507, 41-49 (2016).

20. Deliormanli A.M., In vitro assessment of degradation and bioactivity of robocast bioactive glass scaffolds in simulated body fluid, Ceram. Int. 38, 6435-6444 (2012).

21. Kokubo T. and Takadama H., "How useful is SBF in predicting in vivo bone bioactivity" Biomaterials; 27, 29072915(2006).

22. Xiu, T., Liu, Q. and Wang, J., Comparisons between surfactant-template mesoporous and conventional sol-gel-derived $\mathrm{CaO}-$ $\mathrm{B}_{2} \mathrm{O}_{3}-\mathrm{SiO}_{2}$ glasses: Compositional, textural and in vitro bioactive properties, Journal of Solid State Chemistry, 181, 863-870 (2008).

23. Manupriya, K.S., Thind, K., Singh,V., Kumar, G., Sharma D.P., Singh, Compositional dependence of in-vitro bioactivity in sodium calcium borate glasses, J. Phys. Chem. Solids 70, 1137-11(2009).

24. Murugan R. and Ramakrishna S., Aqueous mediated synthesis of bio resorbable nano crystalline hydroxyapatite, Journal of Crystal Growth 274, 209-13, (2005).

25. Liu D., Troczynski T. and Tseng W., Egypt. J. Biophys. Biomed. Eng., Vol. 18 (2017)
Water-based sol-gel synthesis of hydroxyapatite: process development, Biomaterials 22, 1721-1730 (2001).

26. Hench L., Bioceramics: From concept to clinic, Journals of American Ceramic Society 74, 1487-1510 (1991).

27. Sampath T., Manjubala I. and Gunasekaran J., synthesis of carbonated calcium phosphate ceramics using microwave irradiation, Biomaterials 21, 1623-1629 (2000).

28. Rehman I. and Bonfield W., Analysis of in vitro reaction layers formed on bioglass using thin film x-ray diffraction and ATRFTIR microspecroscopy, journal of materials science: materials in medicine 8, 1-4 (1997).

29. Liu Y., Wang W., Zhan Y., Zheng C. and Wang G., Simple route to hydroxyapatite nano fiber, Materials Letters 56, 496-501 (2002).

30. Nelson D. and Featherstone J., Preparation, analysis, and characterization of carbonated apatites, Calcif. Tissue Int. 34, 69-81 (1982).

31. Lafon J., Champion E., and BernacheAssollant D.,Processing of AB-type carbonated hydroxyapatite $\mathrm{Ca}_{10-\mathrm{x}}\left(\mathrm{PO}_{4}\right)_{6-\mathrm{x}}\left(\mathrm{CO}_{3}\right)$ ${ }_{x}\left(\mathrm{OH}_{2-x-2 y}\left(\mathrm{CO}_{3}\right) y\right.$ ceramics with controlled composition, Journal of the European Ceramic Society 28, 139-147 (2008).

32. Hatakeyama,T., Nakamura, K. and Hatakeyama, H., Non-freezing water content of mono- and divalent cation salts of polyelectrolyte-water systems studied by DSC. Thermochimica Acta 253, 137-148 (1995).

33. Kim, S. J., Yoon, S. G. and Kim, S. I., Synthesis and characteristics of interpenetrating polymer network hydrogels composed of alginate and poly(diallydimethylammoniumc hloride). Journal of Applied Polymer Science 91, 3705-3709 (2004).

34. Nakamura, K., Hatakeyama, T. and Hatakeyama, H., Relationship between hydrogen bonding and bound water in polyhydroxystyrene derivatives. Polymer 24, 871-876 (1983).

35. Nigrawal, A., Chandra, P.S. and Chand, N., Mechanical and thermal properties of nanocellulose obtained from sisal fiber reinforced polyvinyl alcohol (PVA) biocomposites. $J$. Sci. Res. Rev. 1 (3), 40-50 (2012). 
36. Mabrouk M., Chejara D.R., Mulla J.A., et al., Design of a novel crosslinked HEC-PAA porous hydrogel composite for dissolution rate and solubility enhancement of efavirenz, International Journal of Pharmaceutics 490, 429437 (2015).

37. Ravindra V. B., Divya B., Dharmesh R., Mostafa Mabrouk , A composite chitosan-gelatin bilayered, biomimetic macroporous scaffold for blood vessel tissue engineering, Carbohydrate Polymers 157, 1215-1225 (2017).

38. Sadanand P. and James R., Sodium alginate stabilized silver nanoparticles-silica nanohybrid and their antibacterialCharacteristics, International Journal of Biological Macromolecules 93, 712723 (2016).

39. Zhou K., Zhang X., Chen Zh., Lei Sh., Li W., Preparation and characterization of hydroxyapatite-sodium alginate scaffolds by extrusion free forming, Ceramics Int. 41 (10), 14029-14034 (2015).

40. Fujimori H., Toya H., Ioku K., Goto S., Yoshimura M., In situ observation of defects in hydroxyapatite up to 1200 oC by ultraviolet Raman spectroscopy, Chemical Physics Letters 325, 383-388 (2000).

41. Zhang J., Tanaka H., Ye F., Jiang D. and Iwasa M., Colloidal processing and sintering of hydroxyapatite, Materials Chemistry and Physics, 101, 69-76 (2007).

42. Sowmya S., Jayasree R., Chennazhi K.P., Nair S.V. and Jayakumar R., Biocompatible alginate/ nano bioactive glass ceramic composite scaffolds for periodontal tissue regeneration, Carbohydrate Polymers 87, 274-283 (2012).

43. Li, Y., Zuo, Y. and Wei, J., Preparation of nano-hydroxyapatite/polyamide composite biomaterial. China Patent No. 5, 1011-1033 (2003).

44. Kim, S., Kang, Y. and Krueger, C.A., Sequential delivery of BMP-2 and IGF-1 using a chitosan gel with gelatin microspheres enhances early osteoblastic differentiation. Acta Biomater 8, 17681777(2012).

45. Kim, S-S., Park, MS., Jeon, O., Choi, C.Y. and Kim, B.S., Poly (lactidecoglycolide)/ hydroxyapatite composite scaffolds for bone tissue engineering. Biomaterials 27, 1399-409 (2006).
46. Nandi, S. K., Kundu, B., Datta,S., De, D. $\mathrm{K}$. and Basu, D., The repair of segmental bone defects with porous bioglass: an experimental study in goat. Research in Veterinary Science 86, 162-173 (2009).

47. Davidovich-Pinhas, M. and Bianco-Peled, H., A quantitative analysis of alginate swelling. Carbohydrate Polymers, 79, 1020-1027 (2010).

48. Lee, K. Y. and Mooney, D. J., Alginate: Properties and biomedical applications. Progress in Polymer Science 37, 106-126 (2011).

49. Mabrouk M., Choonara Y. E., Pradeep K., Lisa C. and Viness P., The Influence of Lyophilized EmuGel Silica Microspheres on the Physicomechanical Properties, In Vitro Bioactivity and Biodegradation of a Novel Ciprofloxacin-Loaded PCL/PAA Scaffold. Polymers, 8(6), 232 (2016).

50. Darilis S., Kara B. and Eiji S., Controlled nucleation of hydroxyapatite on alginate scaffolds for stem cell-based bone tissue engineering. J. Biomed Mater Res A 95(1), 222-34 (2010).

51. Mabrouk M., Mostafa A.A., Oudadesse H., Mahmoud A.A. and El-Gohary M.I., Effect of ciprofloxacin incorporation in PVA and PVA bioactive glass composite scaffolds. Ceramics International 40, 4833-4845 (2014).

52. Heo E. Y., KO N. R. and Bae M. S., Novel 3D printed alginate-BFP1 hybrid scaffolds for enhanced bone regeneration. Journal of Industrial and Engineering Chemistry 45, 61-67 (2017).

(Received 27/11/2017; Accepted 11/12/2017) 
دراسة الخواص لسقالات جديده محضره من خليط مواد عضوية وغير عضوية خارج جسم الكائن الحي لتجديد العظام

'خيري محمد تهامي', اسلام سليمان السيد', مصطفي مبروك محمدّ ' محمد عبدالحميد

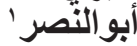

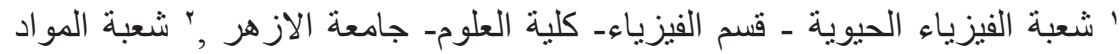

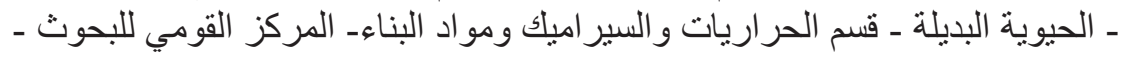

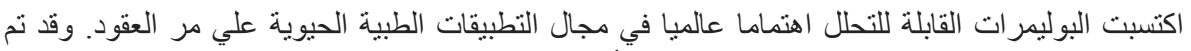

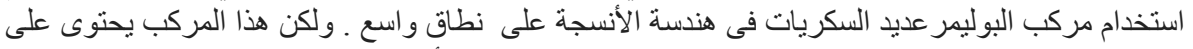

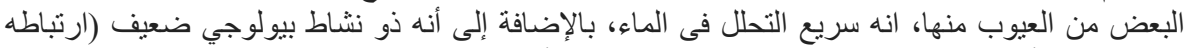

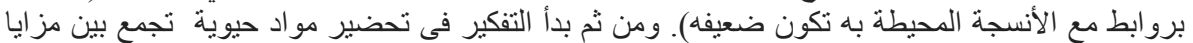

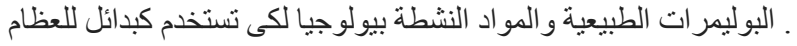

في هذه الدراسة، تم تحضير سقالات مركبه من البوليمر ات عديدة السكريات و الهيدروكسي اباتيت باستخدام

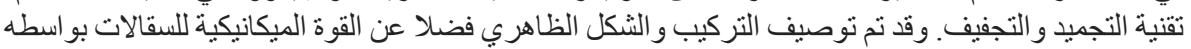

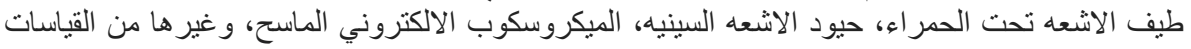

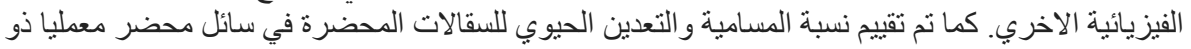
تركيز املاح مشابها لتركيز املاح بلازما دما دم الانسان.

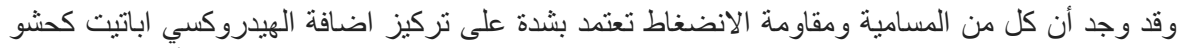

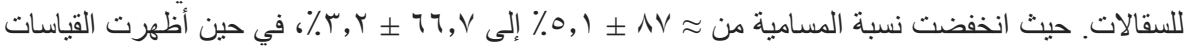

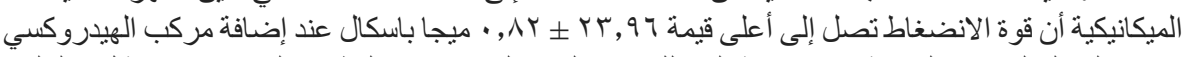

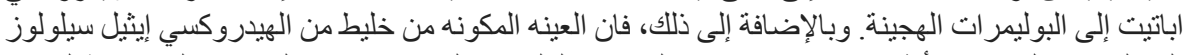

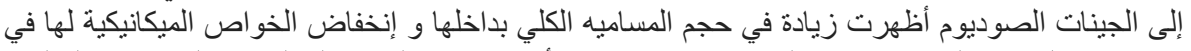

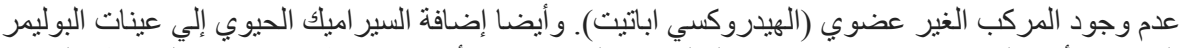
المحضرة أدت إلي زيادة ترسيب عنصري الكالسيو و الفو سفور مما أدي تكوين طبقه الاباتيت علي سطح العينات المخرة.

وبالتالي فقد أوضحت النتائج إلى أن هذه السقالات المركبة من البوليمرات عديدة السكريات والمضاف الئهات اليها

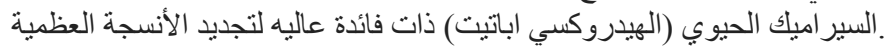

